\title{
Two well-differentiated pancreatic neuroendocrine tumor mouse models
}

\author{
Chung Wong ${ }^{1,11} \cdot$ Laura H. Tang ${ }^{2}$. Christian Davidson ${ }^{3}$ Evan Vosburgh $\mathbb{1}^{1,4,5,12} \cdot$ Wenjin Chen ${ }^{4,6}$ - David J. Foran ${ }^{4,6}$. \\ Daniel A. Notterman ${ }^{7}$. Arnold J. Levine ${ }^{8}$ - Eugenia Y. Xu $\mathbf{X}^{1,4,9,10}$
}

Received: 18 January 2019 / Revised: 26 April 2019 / Accepted: 7 May 2019 / Published online: 3 June 2019

(c) ADMC Associazione Differenziamento e Morte Cellulare 2019. This article is published with open access

\begin{abstract}
Multiple endocrine neoplasia type 1 (MEN1) is a genetic syndrome in which patients develop neuroendocrine tumors (NETs), including pancreatic neuroendocrine tumors (PanNETs). The prolonged latency of tumor development in MEN1 patients suggests a likelihood that other mutations cooperate with Menl to induce PanNETs. We propose that Pten loss combined with Menl loss accelerates tumorigenesis. To test this, we developed two genetically engineered mouse models (GEMMs)-MPR (Men $1^{f l o x f f l o x}$ Pten $^{f l o x f f l o x}$ RIP-Cre) and MPM (Men $1^{f l o x}$ fflox Pten $^{f l o x f f l o x}$ MIP-Cre) using the Cre-LoxP system with insulin-specific biallelic inactivation of Menl and Pten. Cre in the MPR mouse model was driven by the transgenic rat insulin 2 promoter while in the MPM mouse model was driven by the knock-in mouse insulin 1 promoter. Both mouse models developed well-differentiated (WD) G1/G2 PanNETs at a much shorter latency than Men1 or Pten single deletion alone and exhibited histopathology of human MEN1-like tumor. The MPR model, additionally, developed pituitary neuroendocrine tumors (PitNETs) in the same mouse at a much shorter latency than Menl or Pten single deletion alone as well. Our data also demonstrate that Pten plays a role in NE tumorigenesis in pancreas and pituitary. Treatment with the mTOR inhibitor rapamycin delayed the growth of PanNETs in both MPR and MPM mice, as well as the growth of PitNETs, resulting in prolonged survival in MPR mice. Our MPR and MPM mouse models are the first to underscore the cooperative roles of Menl and Pten in cancer, particularly neuroendocrine cancer. The early onset of WD PanNETs mimicking the human counterpart in MPR and MPM mice at 7 weeks provides an effective platform for evaluating therapeutic opportunities for NETs through targeting the MENIN-mediated and PI3K/AKT/mTOR signaling pathways.
\end{abstract}

Edited by G. Melino

Supplementary information The online version of this article (https:// doi.org/10.1038/s41418-019-0355-0) contains supplementary material, which is available to authorized users.

Eugenia Y. Xu

exu@princeton.edu

1 Raymond and Beverly Sackler Foundation Laboratory, New Brunswick, NJ 08901, USA

2 Department of Pathology, Memorial Sloan-Kettering Cancer Center, New York, NY 10065, USA

3 Department of Pathology, University of Utah, Huntsman Cancer Institute, Salt Lake City, UT 84112, USA

4 Rutgers Cancer Institute of New Jersey, Rutgers, the State University of New Jersey, New Brunswick, NJ 08903, USA

5 Department of Medicine, Robert Wood Johnson Medical School, Rutgers, the State University of New Jersey, New Brunswick, NJ 08901, USA

6 Department of Pathology and Laboratory Medicine, Robert Wood

\section{Introduction}

Neuroendocrine tumors (NETs) constitute a heterogeneous group of neoplasms that can arise from the NE cells found

Johnson Medical School, Rutgers, the State University of New Jersey, New Brunswick, NJ 08901, USA

7 Department of Molecular Biology, Princeton University, Princeton, NJ 08544, USA

8 School of Natural Sciences, Institute for Advanced Study, Princeton, NJ 08540, USA

9 Department of Pediatrics, Robert Wood Johnson Medical School, Rutgers, the State University of New Jersey, New Brunswick, NJ 08901, USA

10 Present address: Department of Molecular Biology, Princeton University, Princeton, NJ 08544, USA

11 Present address: Regeneron Inc., Tarrytown, NY 10591, USA

12 Present address: Department of Medicine, Yale University School of Medicine, New Haven, CT 06510, USA 
in numerous tissues throughout the body including the gastroenteropancreatic tract, bronchopulmonary system, pituitary, parathyroids, thyroid, and ovaries. Pancreatic NETs (PanNETs) are found in the gastroenteropancreatic tract. Human pancreatic NE neoplasms are classified as either well-differentiated (WD) tumor (WD-NET) or poorly differentiated (PD) carcinoma (PD-NEC) [1]. WD PanNETs can be functional, secreting biologically active hormones such as insulin, glucagon, and others, or non-functional. PD-PanNECs are genetically and biologically related to conventional carcinoma with worse clinical prognosis [2]. Based on Ki 67 index, WD PanNETs are graded as G1 $(<3 \%)$, G2 $(3-20 \%)$, or G3 $(>20 \%)[3,4]$.

When surgery is not an option, the Food and Drug Administration has three approved drugs to treat progressive PanNETs: everolimus (rapamycin analog), sunitinib, and radiotherapy Lutathera (somatostatin analogs) [5-8]. The preclinical efficacy of rapamycin and sunitinib was demonstrated using the human BON-1 xenograft and RIP-Tag2 mouse models [9-13]. These mice develop PanNETs with poorly differentiated and high-grade histology, which do not resemble the counterpart of human PanNETs $[14,15]$. Additional preclinical murine models that more closely reflect the histology and behavior of human WD PanNETs are needed.

Multiple endocrine neoplasia type 1 (MEN1) is an autosomal-dominant inherited syndrome with manifestation of NETs that involve at least two of the four endocrine glands, frequently parathyroid glands, endocrine pancreas, anterior pituitary, and adrenal gland [16-19]. The MEN1 gene is responsible for the syndrome. Its gene product, MENIN, is a highly conserved tumor suppressor [20]. Biallelic inactivation of MEN1 occurs in $44 \%$ of human PanNETs, inherited or sporadic, and is sufficient to drive tumorigenesis with long latency [21]. The delayed latency of NET development suggests that additional molecular and genetic events might be required for tumorigenesis.

The human and mouse genes share a highly conserved genomic structure with $89 \%$ nucleotide sequence homology and $97 \%$ amino acid sequence homology, respectively [22]. Mouse strains with defective Menl possess remarkable phenotypic and histological overlap with the human MEN1 syndrome. Heterozygous Men1 mice or homozygous $\beta$-cellspecific Menl deletion mice develop WD PanNETs and pituitary neuroendocrine tumors (PitNETs) also with long latency [23-28] as human MEN1 patients.

The tumorigenic latency in the Men1 mouse model makes it less ideal for the preclinical testing of candidate drugs. Identifying genes that function cooperatively with Menl could help us develop a better preclinical WD PanNET mouse model. In seeking targets, we consider the phosphoinositide 3-kinase (PI3K)/protein kinase B (AKT)/ mammalian target of rapamycin (mTOR) signaling pathway, the second most mutated pathway in cancer, after p53 [29]. The mTOR pathway plays an important role in human NETs based on genome sequencing [21, 30-34]. Additionally, an mTOR inhibitor, everolimus, is used to treat PanNET patients. Phosphatase and tensin homolog (PTEN), a key negative regulator of the PI3K/AKT/mTOR pathway, is frequently mutated or lost in several familial or sporadic cancer types; however, in PanNETs, the frequency of loss is low, 7-26.4\% [21, 32-38]. Co-mutations of MEN1 and PTEN have been observed in a small percentage of human PanNETs [21, 32]. Thus we hypothesize that Menin and Pten may function cooperatively to suppress NE tumorigenesis.

Here we generated two genetically engineered mouse models (GEMMs) harboring homozygous deletions of Menl and Pten within insulin-producing $\beta$-cells and compared histopathology with the Men1 and Pten mouse models. Concomitant loss of Pten and Menl accelerated NE tumorigenesis. These GEMMs could provide improved preclinical therapeutic models for WD PanNET.

\section{Methods and materials}

\section{Animals}

To generate compound mice Men $1^{\text {floxflox }}$ Pten ${ }^{f l o x}$ flox $\mathrm{RIP}-\mathrm{Cre}$ (MPR) (Supplementary Fig. S1A), Men $1^{\text {floxflox }}$ mice (129S (FVB)-MenI $1^{\text {tml.2Ctre }} / \mathrm{J}$, stock number 005109, The Jackson Laboratory, USA) were first crossed with Pten ${ }^{f l o x f f l o x}$ mice

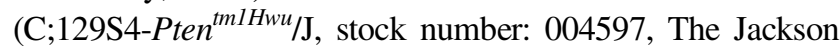
Laboratory, USA) to generate heterozygous Men1 ${ }^{+/ f l o x}$ Pten $^{+f f l o x}$ mice. The resulting mice were then intercrossed to generate Men $I^{\text {floxfflox }}$ Pten $^{\text {floxfflox }}$ (MP) mice. The resulting homozygous mice were then crossed with RIP-Cre mice (C57BL/6-Tg(Ins2-cre) 25Mgn/J, stock number: 003573, The Jackson Laboratory, USA) to generate $M e n 1^{+/ f l o x}$ Pten $^{+ \text {fflox }}$ RIP-Cre mice. These mice were further crossed back to MP mice to generate the desired MPR compound mice and corresponding littermates MP. Confirmation of the genotypes in mice was evaluated by PCR using tail genomic DNA (Supplementary Fig. S1B). Tissue-specific deletion of Menl and/ or Pten genes was confirmed by PCR using genomic DNA from various organs. Supplementary Fig. S1C showed that Menl and Pten genes were specifically deleted in pancreatic islets and brain, but not in heart, intestine, kidney, liver, lung, spleen, and pancreatic exocrine tissues in the representative MPR mice. This is consistent with the previous report that RIP-Cre is specifically expressed in pancreatic islets and hypothalamus $[24,39]$.

Pten $^{\text {flox } f \text { flox }}$ RIP-Cre (PR) mice were produced by generating heterozygous Pten $^{+/ f l o x}$ RIP-Cre animals by the first 
cross of Pten ${ }^{\text {floxflox }}$ mice with RIP-Cre mice, then by crossing the resulting Pten ${ }^{+/ f l o x}$ RIP-Cre mice with Pten $^{\text {floxflox }}$ mice. Men $1^{f l o x f f o x}$ RIP-Cre (MR) mice were produced similarly as the strategy to produce PR mice. The same strategy was taken to generate compound mice Men $1^{f l o x f f l o x}$ Pten $^{f l o x f f l o x}$ MIP-Cre (MPM), Men $1^{\text {flox } f f l o x}$ MIP-Cre (MM), and Pten ${ }^{f l o x}$ flox MIP-Cre (PM), except that MIP-Cre (B6

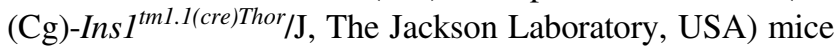
were used instead of RIP-Cre mice. To generate MPM, MM, and PM mice more quickly, first-generation MPM, MM, or

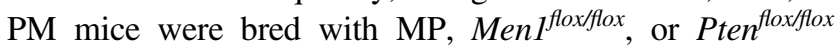
mice, respectively, to obtain second-generation MPM, MM, or PM mice for the experiments. Animals were genotyped by using vendors' recommended primers (The Jackson Laboratory, USA) [40] and standard genomic PCR techniques. All cohorts were in a mixed genetic background. Animals were housed in a temperature-, humidity-, and light-controlled room (12-h light/dark cycle), allowing free access to food and water.

Mice were studied alongside age- and sex-matched control animals unless otherwise indicated.

All animal experiments were conducted according to the research guidelines set forth by the Institutional Animal Care and Use Committee (IACUC) of Rutgers, the State University of New Jersey, USA.

\section{Evaluation of pituitary size}

A ruler was used to measure the size of a pituitary at autopsy. The volume of a pituitary was calculated with the formula $V=(\pi / 6) \times($ length $\times$ width $\times$ height $)$. The dimensions of a normal pituitary are: $3-3.5 \mathrm{~mm}$ in length, $1-1.5$ $\mathrm{mm}$ in width and depth.

\section{Evaluation of PanNET formation}

To score PanNETs, three 120- $\mu \mathrm{m}$ apart pancreas sections from each mouse were stained with hematoxylin and eosin $(\mathrm{H} \& \mathrm{E})$, glucagon, and insulin. The sections were evaluated histologically. One or more islets of $\geq 1 \mathrm{~mm}$ in diameter with loss of $\alpha$-cells (negative immunoreactivity for glucagon) and clonal proliferation of $\beta$-cells (positive immunoreactivity for insulin) in any of the three sections were considered as tumor development (PanNET) in that mouse.

\section{Histology and immunohistochemistry (IHC)}

Tissues were fixed in 10\% buffered formalin solution (Fisher Scientific, Inc., USA) for $24 \mathrm{~h}$ at room temperature or for $48 \mathrm{~h}$ at $4{ }^{\circ} \mathrm{C}$. Fixed tissues were then washed in $50 \%$ ethanol and transferred to $70 \%$ ethanol for paraffin embedding. For IHC, paraffin-embedded tissues were cut into 4- $\mu \mathrm{m}$ sections and stained with H\&E. All IHC staining was performed on $4-\mu \mathrm{m}$ paraffin-embedded sections and placed on charged glass slides. Sections were de-waxed with histoclear (National Diagnostics, Inc., USA) and rehydrated through graded alcohol. Antigen retrieval was then performed by incubating the slides in antigen retrieval solution (Vector Labs, USA) at $95^{\circ} \mathrm{C}$ for $15 \mathrm{~min}$. Slides were then allowed to cool for $20 \mathrm{~min}$ on ice. After washing in phosphate-buffered saline (PBS) with $0.1 \%$ Tween 20 , the slides were blocked with a $3 \%$ hydrogen peroxide solution for $10 \mathrm{~min}$. The slides were then washed in PBS with $0.1 \%$ Tween 20 . The endogenous biotin activity was inactivated using the Endogenous Biotin Blocking Kit (Invitrogen, Inc., USA). The following detection and visualization procedures were performed according to the manufacturers' protocol. Slides were counterstained in Gill's hematoxylin, dehydrated, cleared, and cover-slipped. Negative control slides were run without primary antibody. Control slides known to be positive for each antibody were incorporated. DAKO antibodies (Fisher Scientific, USA): Insulin (A0564), Prolactin (A0569), and Growth hormone (GH) (A0570); Cell Signaling antibodies (Cell Signaling Technology Inc., Danvers, MA, USA): Glucagon (2760), Pten (9559); Abcam antibodies: Chromograinin A (ab15160), Ki 67 (ab15580), adrenocorticotropin hormone (ACTH) (ab74967); synaptophysin (Roche, 790-4407, USA); and Menin (Bethyl Lab, a300-105a) were used.

\section{Proliferation index}

For quantification of IHC positive staining for Ki 67, the areas with the highest density of Ki 67 reactivity among tumor cells were first identified. At least 1000 cells were counted at $\times 20$ magnification in these high Ki 67 density areas in a minimum of three mice of each genotype and sex.

\section{Ratio of the islets area per pancreas area}

IHC-insulin-stained pancreas sections from three $120-\mu \mathrm{m}$ apart sections per mouse (three or more samples of each genotype and sex were used) were digitized at $\times 20$ at Rutgers Cancer Institute of New Jersey Biomedical Informatics shared resource using an Olympus VS120 whole slide scanner (Olympus Corporation of the Americas, Center Valley, PA). The image analysis algorithm was custom developed on Visiopharm image analysis platform (Visiopharm A/S, Hoersholm, Denmark). Insulinpositive pancreatic islets were digitally recognized and outlined. The diameter and area of individual islets were measured accordingly, and the area of the whole pancreas was measured as well. For quantitative analysis, the isletsto-pancreas ratio was calculated and graphed. 


\section{Molecular analysis}

Genomic DNA was isolated using the QIAamp DNA Mini Kit (Qiagen, USA) and total RNA was isolated using the RNeasy Mini Kit (Qiagen, USA) per the manufacturer's instruction. PCR fragments from genomic DNA were amplified using a thermal cycler (Veriti, the Applied Biosystems, USA) $\left(94{ }^{\circ} \mathrm{C}, 3 \mathrm{~min} ; 94^{\circ} \mathrm{C}, 30 \mathrm{~s}, 60{ }^{\circ} \mathrm{C}, 1 \mathrm{~min}\right.$, $72{ }^{\circ} \mathrm{C}, 1 \mathrm{~min}$, for 40 cycles; $72{ }^{\circ} \mathrm{C}, 7 \mathrm{~min}$ ). cDNA was synthesized from $1 \mu \mathrm{g}$ of total RNA using TaqMan ${ }^{\circledR}$ Reverse Transcription Reagents (Life Technologies, Grand Island, NY, USA) per the manufacturer's instruction. Realtime PCR was performed as described before [41]. All experiments were performed in triplicate and each experiment was repeated at least twice independently.

\section{Western blot analysis}

Protein lysates were made from tissues and tumor samples using RIPA lysis buffer (ThermoFisher Inc., USA) containing the complete protease inhibitor cocktail (Roche, USA) and the PhosSTOP phosphatase inhibitor cocktail (Roche, USA). Ten $\mu$ g of protein lysate was loaded onto sodium dodecyl sulfate-polyacrylamide gel electrophoresis gels and transferred to polyvinylidene difluoride membrane for immunoblotting as described previously [41]. Membranes were probed with antibodies. The following antibodies were purchased from Cell Signaling Technology Inc. (Danvers, MA, USA): AKT, p-AKT (S473), p-RPS6 (S235/ 236), RPS6, PTEN. Antibody against Menin was purchased from Bethyl Laboratories, Inc. (Montgomery, TX, USA). GAPDH protein was used as a loading control for immunoblots in all the experiments. All the experiments were repeated at least twice independently.

\section{Serum assays}

Since MPR mice showed lethargic symptom after 9 weeks, to make sure MPR mice were alive for glucose measurement and blood collection for serum assays, all MPR, control MP littermates, MR, and PR mice were fasted for $3-5 \mathrm{~h}$ in the morning before blood collection. MPM and control MP littermates were fasted for $16 \mathrm{~h}$ before blood collection. Blood glucose was measured with ONE TOUCH Ultra2 blood glucose meter (Lifescan, Inc., USA). Using the manufacturer's instructions, serum insulin levels were determined with an ultrasensitive mouse insulin ELISA Kit (Crystal Chem Inc., 90080, USA). Serum prolactin, GH, and $\mathrm{ACTH}$ levels were measured using commercial kits from Calbiotech (PR063F-100, USA), Millipore (EZRMGH-45K, USA), and Lifespan Biosciences Inc. (LSF5354, USA), respectively. Serum insulin, prolactin, and GH levels were repeated at least twice independently.
Serum ACTH levels was performed once due to limitation of serum.

\section{Rapamycin treatments}

The in vivo efficacy of rapamycin treatment on NETs was evaluated in MPR mouse model. One trial was on 4-5week-old MPR mice and the other was on 7-9-week-old mice. Vehicle and rapamycin (LC Laboratories Inc., Woburn, MA, USA) (15 mg/kg, QWK, I.P.) was injected into mice weekly. Body weight was measured once per week. Pituitary size was measured at autopsy using a ruler. Pituitary and pancreas were examined macroscopically at autopsy. Paraffin-embedded sections were evaluated histologically after $\mathrm{H} \& \mathrm{E}$ and IHC staining.

The in vivo efficacy of rapamycin was similarly evaluated in the MPM mouse model. Treatments were performed on 4-week-old MPM mice. Pancreas was examined at autopsy macroscopically. Paraffin-embedded sections were evaluated histologically after H\&E and IHC staining.

\section{Statistical analysis}

Graphs were produced using the GraphPad Prism version $6.0 \mathrm{~b}$ software. The statistical significance of survival curves between two groups was analyzed using log-rank (MantelCox) test, and the statistical significance of pituitary size between two groups was analyzed using unpaired $t$ test with Welch's correction by the GraphPad Prism_6.0b software. $p<0.05$ was considered significant.

\section{Results}

\section{Pten and Men 1 function cooperatively to accelerate PitNETs and death}

To test our hypothesis that Pten and Menin may function cooperatively to suppress NE tumorigenesis, we investigated whether the MPR compound mice developed NETs earlier than MR or PR mice. We monitored survival of a cohort of MPR mice, alongside MP mice, the single MR or PR deletion mice. MPR mice started dying at 9 weeks and did not live beyond 23 weeks (Fig. 1a), while control MP, $\mathrm{MR}$, and PR mice did not die during the study period, consistent with other studies [25, 42]. Quantitative mRNA and western blot analysis confirmed that Men1 and/or Pten expression was knocked down in the pituitary in representative MPR, MR, and PR mice (Fig. 1b, c). The median survival of MPR mice was 14 weeks. Among the 70 (38F/ $32 \mathrm{M})$ lethargic MPR mice, 58 mice $(83 \%, 35 \mathrm{~F} / 23 \mathrm{M})$ showed symptoms such as blindness, tilted head/body, 
a

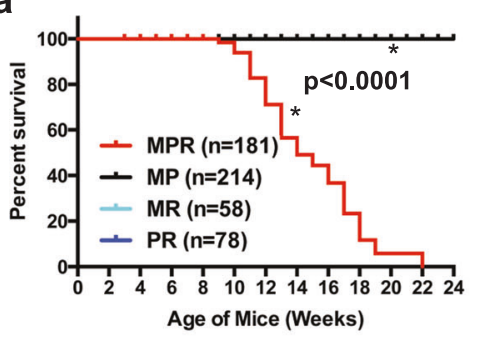

d

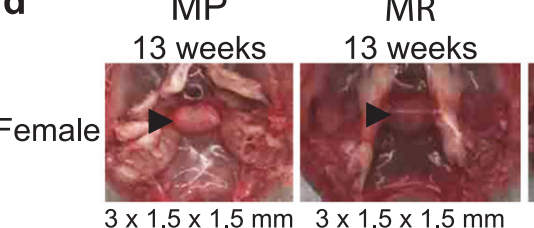

$3 \times 1.5 \times 1.5 \mathrm{~m}$
23 weeks

Male

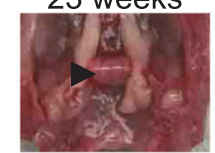

$3 \times 1 \times 1 \mathrm{~mm}$

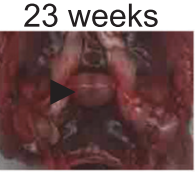

$3.5 \times 1.5 \times 1.5 \mathrm{~mm}$ b

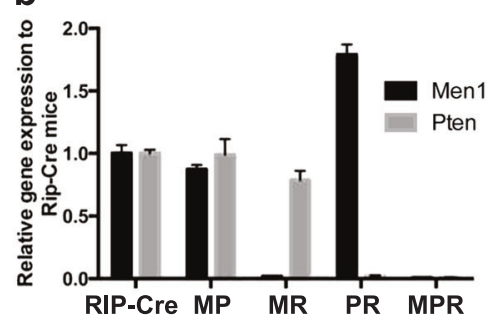

PR
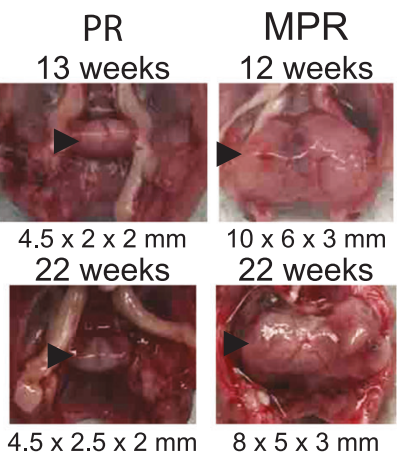
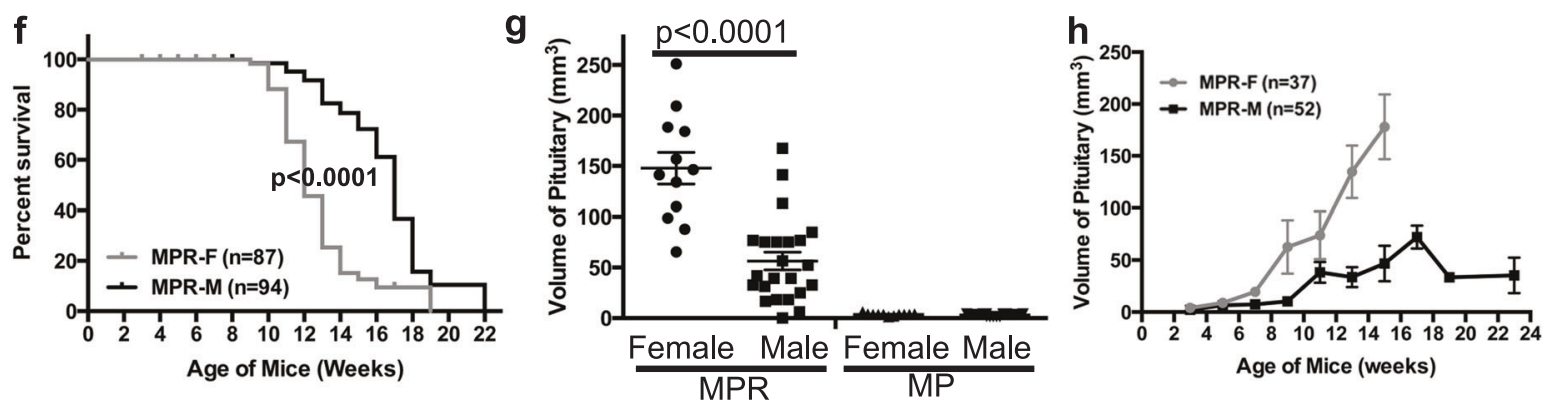

i
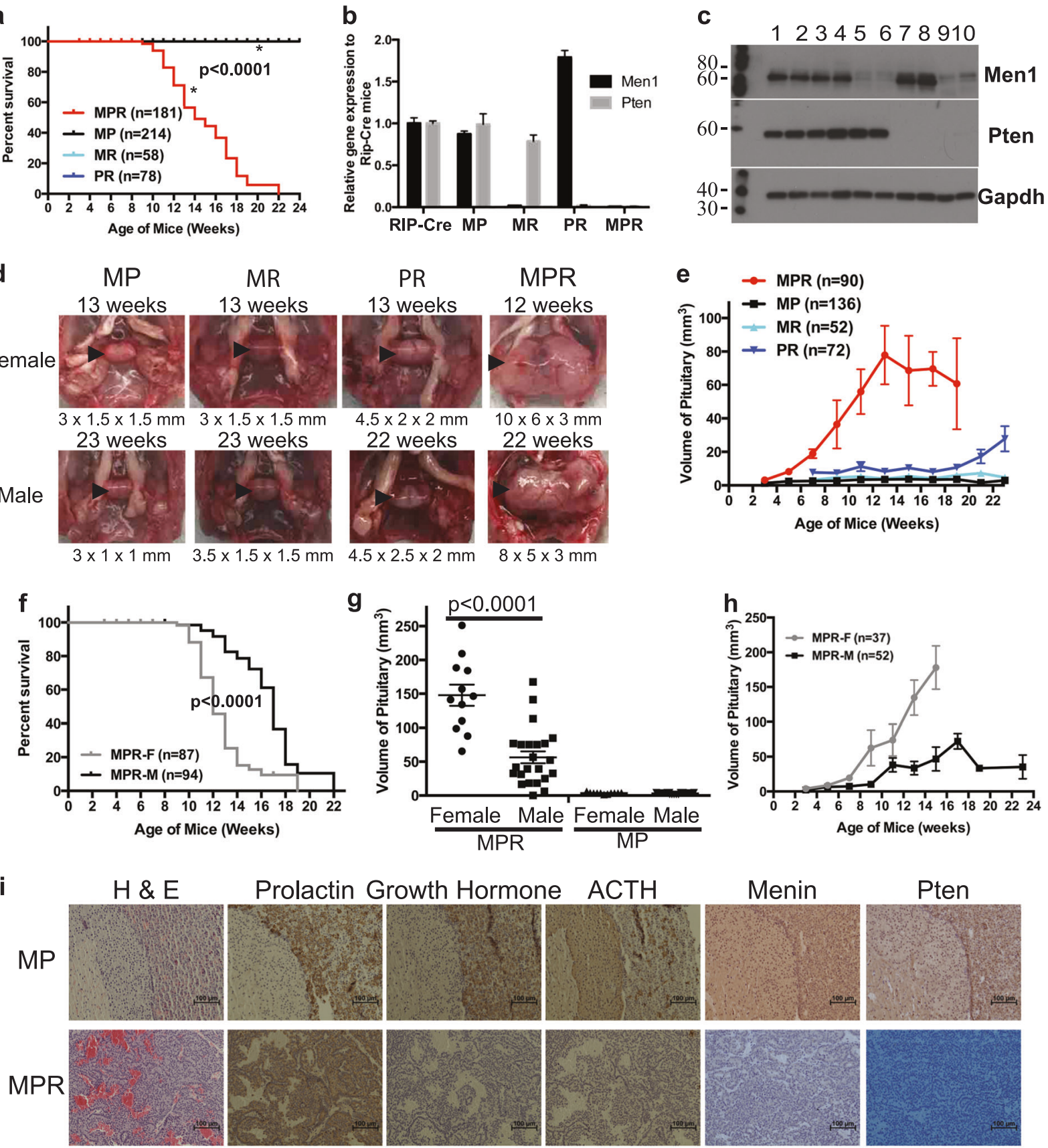

j
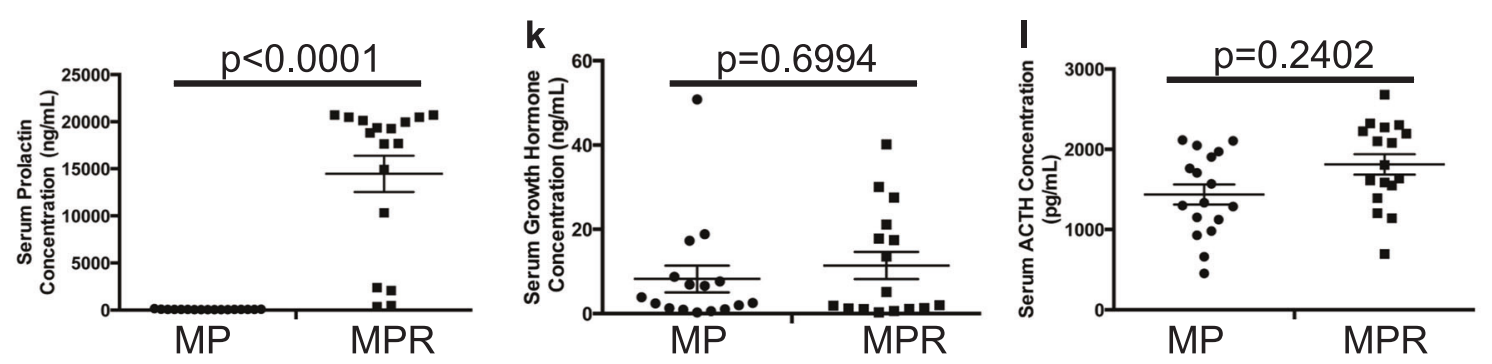

circular gait path, and hind legs paralysis-symptoms consistent with those described in human patients with PitNETs. Autopsy of lethargic mice revealed PitNETs and dramatically enlarged pituitaries. Control MP, MR, and PR mice displayed normal or only slightly enlarged pituitaries (Fig. 1d). Evaluation of the pituitary size over time in a 
Fig. 1 Concomitant loss of Men1 and Pten decreased survival and accelerated pituitary neuroendocrine tumor (PitNET) development in MPR mice. a Kaplan-Meier survival curves showed significantly shorter life span $(p<0.0001)$ in MPR mice than in MR, PR, and control MP mice. b, c Quantitative mRNA and western blots showed that corresponding Men1 or/and Pten gene/protein was deleted in pituitary in the representative mice of various genotypes. b Quantitative mRNA analysis. c Western blots analysis. Genotypes of each lane: 1 and 2RIP-Cre; 3 and 4-MP; 5 and 6-MR; 7 and 8-PR; 9 and 10-MPR. The molecular weight markers (in $\mathrm{kD}$ ) are labeled on the left side of the blots. d Gross pathology of pituitary is shown from representative MP, MR, PR, and MPR female mice at 12-13 weeks and male mice at 22-23 weeks. Normal pituitary is cylindrical in shape. The size of pituitary under the image was written as length $\times$ width $\times$ height $(\mathrm{mm})$. Pituitary is shown with arrowhead inside the mouse skull. e Evaluation of the size of pituitaries in 2-week interval starting at 3 weeks (MPR and MP mice) or 7 weeks (MR and PR mice) showed that PitNETs developed dramatically faster and larger in MPR mice. f Kaplan-Meier survival curves demonstrated that female MPR mice had significantly shorter life span $(p<0.0001)$ than male MPR mice. $\mathbf{g}$ Size of pituitary at death in female $(n=12)$ and male $(n=23)$ MPR mice, as well as age-matched female $(n=11)$ and male $(n=23)$ MP mice. $\mathbf{h}$ Evaluation of the size of pituitaries in female and male MPR mice at scheduled autopsy $(n=37$ for female mice with $n=4,6,7,7,4,7,2$ at 3, 5, 7, 9, $11,13,15$ weeks, respectively; $n=52$ for male mice with $n=3,4,3,7$, $4,9,10,9,1,0,2$ at $3,5,7,9,11,13,15.17,19,21,23$ weeks respectively). i Immunohistochemical staining of prolactin, growth hormones, adrenocorticotropin hormone (ACTH), and Men1 and Pten on pituitary sections in MP and MPR mice. $\mathbf{j}-\mathbf{l}$ Serum hormone levels in MP and MPR mice confirmed that these PitNETs were prolactinomas. j Prolactin; k Growth hormone; 1 ACTH. MPR Men $1^{\text {floxfflox }}$

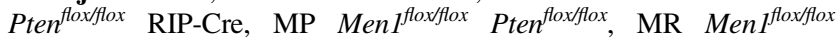
RIP-Cre, PR Pten ${ }^{\text {flox } f \text { lox }}$ RIP-Cre

cohort of MPR, PR, MR, and MP mice showed that pituitaries grew dramatically faster and larger in MPR mice (Fig. 1e). PR mice showed slightly faster and bigger pituitaries than that in MR and control MP mice during the study period, suggesting that Pten plays a role in suppressing pituitary tumorigenesis. Concomitant loss of Pten and Men I in mice resulted in earlier onset of PitNETs and death compared to MR and PR mice.

Consistent with the human MEN1 syndrome [43], MPR mice recapitulated a gender bias in tumor development. Assessment of Kaplan-Meier survival (KMS) curves confirmed shortened survival in female vs. male MPR mice (Fig. 1f). Median survival was 12 weeks for females and 17 weeks for males. The PitNETs in female lethargic MPR mice were more than two-fold larger than that in male ones at death, while control female and male MP mice had the same normal size of pituitaries (Fig. 1g). Evaluation of the pituitary size over time in a cohort of MPR mice showed that pituitaries grew faster and larger in female than in male MPR mice (Fig. 1h). This gender bias has also been reported in MR mice [25] and observed in PR mice (Fig. 1d).

To understand the pituitary origin of these tumors, the PitNETs from lethargic MPR mice ( $n=26,14 \mathrm{~F} / 12 \mathrm{M})$ and the pituitaries from control MP mice were IHC stained for prolactin, GH, and ACTH. Control MP mice showed staining consistent with a normal pituitary-heterogeneous expression of prolactin, GH, and ACTH in the anterior lobe, positive expression of ACTH in the intermediate lobe, and no expression of prolactin, $\mathrm{GH}$, and ACTH in the posterior lobe (Fig. 1i and Supplementary Fig. S2). PitNETs from both female and male MPR mice showed positive staining of prolactin and negative staining of $\mathrm{GH}$ and ACTH (Fig. 1i). Evaluation of serum prolactin, GH, and ACTH levels confirmed that these PitNETs were prolactinomas (Fig. $1 \mathrm{j}-1$ ). Thus these PitNETs arose from the pars distalis, mimicking the human MEN1-like syndrome in which prolactinomas are the most common pituitary lesions.

\section{Pten and Men 1 function cooperatively to accelerate PanNETs}

We next investigated the effect of the concomitant loss of Pten and Menin in the pancreas, in comparison with the effect of single Menl or Pten deletion. We evaluated the histopathology of the pancreas for 66 lethargic MPR mice. Fifty-eight mice $(88 \%)$ developed tumors of variable size and number. From 13 to 22 weeks $(n=43)$, these MPR mice developed multifocal pancreatic tumors that were macroscopically (Fig. 2a) similar to tumors found in MR mice at 35 weeks $(11 \%, n=9)$ to after 49 weeks $(93 \%, n=$ $27)$. From 13 to 22 weeks, MR $(n=34)$ and PR $(n=46)$ mice did not show any tumors in the pancreas macroscopically, and evaluation of the histology of pancreas in MR mice $(n=21)$ and PR mice $(n=25)$ did not find any tumors (Fig. 2a and Supplementary Fig. S3A). The protein expression or deletion of Menin and Pten in the islets/ tumors of corresponding genotypes was confirmed using IHC staining. IHC staining in MPR pancreatic tumors indicated clonal insulin immunoreactivity, consistent with $\beta$-cell neoplasia. Immunoreactivity for the $\mathrm{NE}$ markers synaptophysin and chromogranin A indicated that these tumors were PanNETs (Fig. 2b). The Ki 67 index of MPR tumors was between $0.8 \%$ and $6.99 \%$ (Fig. 2b) and of MR tumors was $<2.62 \%$ (Supplementary Fig. S3B). By World Health Organization (WHO) classification [1, 3, 4], MPR tumors were G1/G2 PanNETs while MR tumors were G1 PanNETs. The higher Ki 67 index of MPR tumors suggested a higher proliferation rate than that of MR tumors, which may explain early tumor development in MPR mice than that in MR mice. Loss of Pten accelerated tumorigenesis in the absence of Menl in the pancreas, indicating that Pten and Menl suppress tumorigenesis of the PanNETs cooperatively in mice. Despite accelerated tumorigenesis, MPR mice maintained WD G1/G2 histology.

To evaluate the temporal appearance and frequency of tumor formation in MPR mice, the histology of their 
a

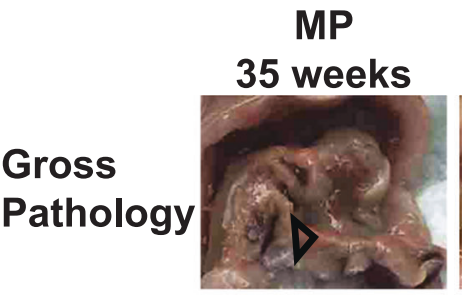

MPR

MR

MR

PR
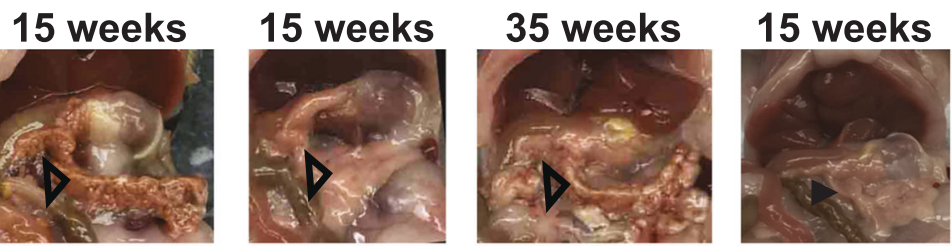

b

$H \& E$
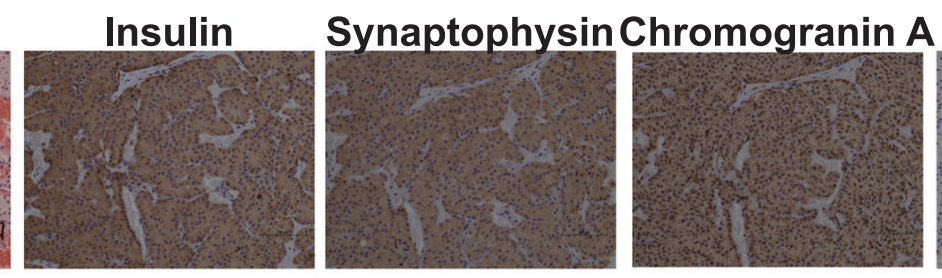

Ki 67

MPR
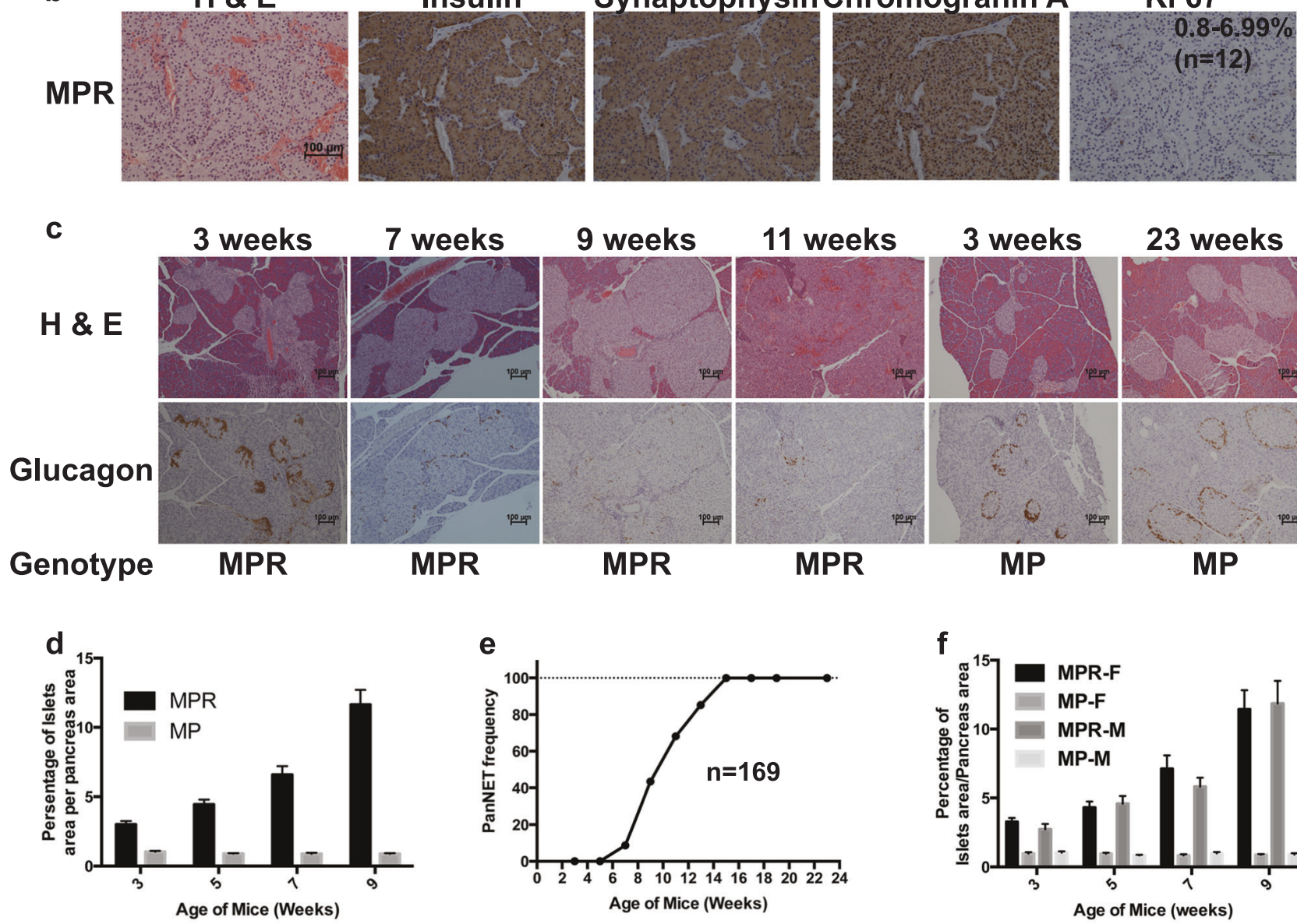

MPR

MPR

MPR

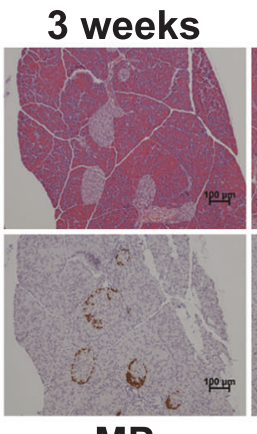

23 weeks

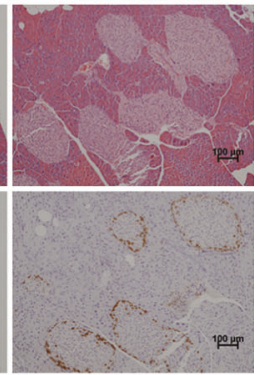

MP

g

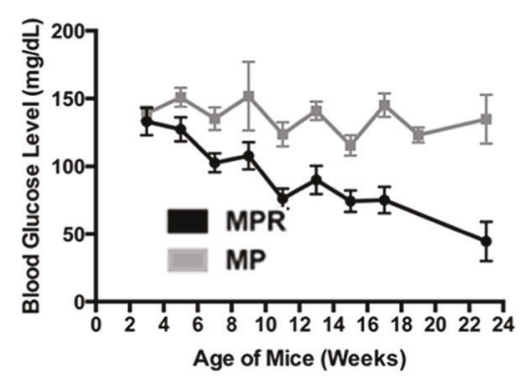

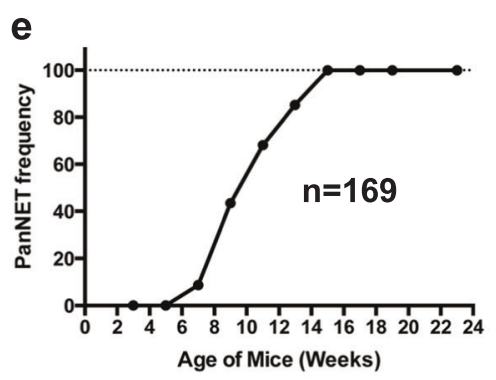

f
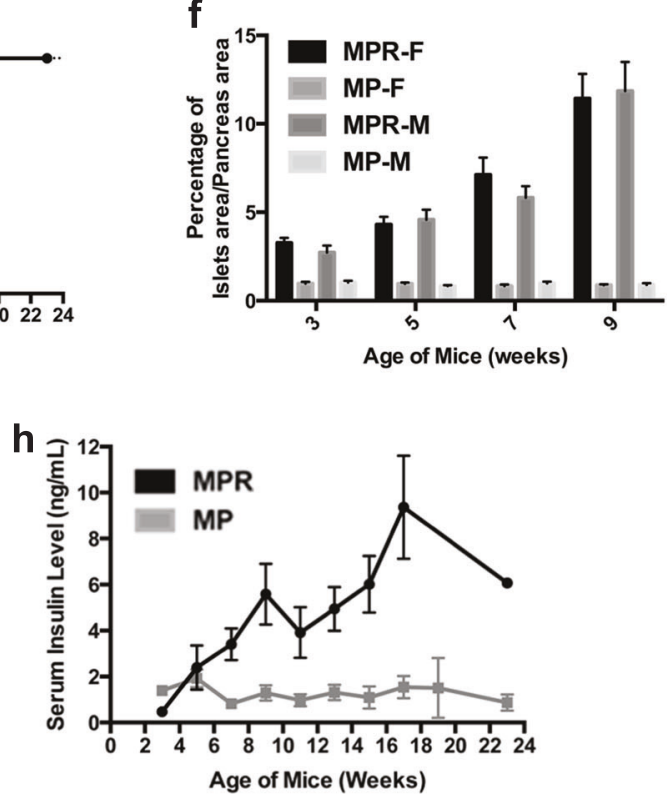

pancreatic islets was evaluated based on $\mathrm{H} \& \mathrm{E}$ and IHC staining of insulin for $\beta$-cells and glucagon for $\alpha$-cells looking at 2-week intervals starting at 3 weeks. Islets from MPR and MP mice showed positive staining for insulin at all time points (Supplementary Fig. S3C). Islets from MP mice were mostly normal with few islets that were mostly round and $<0.2 \mathrm{~mm}$ in diameter with normal peripheral distribution of $\alpha$-cells at any age (Fig. 2c). MPR mice showed hyperplastic islets with increasing numbers of small islets and peripheral $\alpha$-cell distribution starting at 3 weeks. 
Fig. 2 Concomitant loss of Menl and Pten accelerated pancreatic neuroendocrine tumor (PanNET) development in MPR mice. a Gross pathology of pancreas in MP, MPR, MR, and PR mice at 15 or 35 weeks. Pancreas is shown with open triangle inside the mouse abdomen. b Hematoxylin and eosin (H \& E) and immunohistochemical (IHC) staining of insulin and NET markers on MPR pancreatic tumors. Ki 67 index is shown. c H \& E and IHC staining of glucagon of pancreas sections from MPR and MP mice of different ages. d Quantitative comparison of the ratio of the islets area per pancreas area over time in MP and MPR mice ( $n \geq 10$ at each time point). e Frequency of PanNETs in MPR mice at the scheduled autopsy $(n=169$ in total, $n=12,18,23,23,22,27,23,17,2,0,2$ at 3, 5, 7, 9, 11, 13, 15, $17,19,21$ and 23 weeks, respectively). f Quantitative comparison of the ratio of the islets area per pancreas area over time in MPR female and male mice ( $n \geq 5$ at each time point of each genotype and sex). $\mathbf{g}$ Blood glucose levels in MPR mice ( $n=133, n \geq 11$ of each time point (except $n=0$ at 19,21 and $n=2$ at 23 weeks)) and MP mice $(n=133$, $n \geq 11$ of each time point (except $n=4$ at 19,23 and $n=0$ at 21 weeks)) and $\mathbf{h}$ Serum insulin levels in MPR mice $(n=123, n \geq 10$ of each time point (except $n=0$ at 19,21 and $n=1$ at 23 weeks)) and MP mice ( $n=68, n \geq 5$ of each time point (except $n=2$ at 19, $n=0$ at 21 and $n=3$ at 23 weeks)) over time. MPR Ment $1^{\text {flox/flox }}$ Pten $^{\text {floxfflox }}$ RIP-Cre, MP Men $1^{\text {floxfllox }}$ Pten ${ }^{\text {floxflox }}$, MR Men $1^{\text {floxfflox }}$ RIP-Cre, PR Pten ${ }^{f l o x}$ flox $\mathrm{RIP}-\mathrm{Cre}$

As mice aged, they exhibited increasing size and number of hyperplastic islets, neoplastic islets, and more tumors accompanied by a gradual disappearance of $\alpha$-cells (Fig. 2c), indicating a multi-step tumor progression. This was further confirmed by quantitatively measuring the ratio of the islets area per pancreas area (Fig. 2d). Histological evaluation in MPR mice showed tumor onset at 7 weeks $(8.7 \%)$ (Fig. 2e and Table 1), compared to 23 weeks in MR mice [25]. At 15 weeks or later, over 94.7\% MPR mice developed PanNETs. Parallel to PanNET formation, MPR mice gradually developed hypoglycemia and increasing serum insulin levels, while MP mice maintained relatively stable blood glucose and serum insulin levels at all ages (Fig. 2g, h). The MPR PanNETs are insulinomas, similar to mouse MR PanNETs.

\section{Rapamycin treatment resulted in delayed growth of PanNETs and PitNETs}

To assess signaling alterations in MPR PanNETs and PitNETs, we analyzed the in vivo signaling downstream of Pten and Menin. With Pten loss, Akt, a serine-threonine kinase, is aberrantly phosphorylated and activated in response to PI3K activation. Aberrant activation of mTOR signaling leads to the phosphorylation of downstream effector, ribosomal protein S6 (Rps6). We found increased activation of p-Akt and p-Rps6 in PanNETs and PitNETs in MPR mice (Fig. 3a) as expected with disruption of Pten function.

As a proof of concept and to test the efficacy of our model in preclinical assessments, we set up two trials with the MPR mice using the mTOR inhibitor rapamycin to test for anticancer effects. The first trial tested whether rapamycin treatments could inhibit tumor growth in MPR mice. Treatment started at the onset of tumor development (7-9 weeks). We followed the survival on vehicle-treated mice. When vehicle-treated mice were lethargic, sexmatched, rapamycin-treated littermates $(n=7)$ were sacrificed while other rapamycin-treated mice $(n=7)$ remained in the trial and were sacrificed when six of them were lethargic and one was at 30 weeks to end the treatment. The KMS curve indicated that rapamycin treatments increased the life span of MPR mice ( $p<0.003$; Fig. 3b). Autopsy of these treated mice showed that the pituitaries were significantly smaller in rapamycin-treated mice than in vehicle-treated mice $(p<0.001)$ of the same age (Fig. 3c, d). At death, the pituitaries in rapamycin-treated mice were large and the same size as those of the vehicletreated mice $(p=0.50)$. The one rapamycin-treated mouse that was alive at 30 weeks had a small PitNET, further supporting that death of MPR mice was due to development of large PitNETs. Similarly, histological examination of the pancreas showed that rapamycin-treated mice exhibited hyperplastic islets while vehicle-treated mice of the same age had PanNETs. Eventually, the rapamycintreated mice developed PanNETs as well (Fig. 3e). Rapamycin treatment did not show any toxicity based on the measurement of body weight every week (Fig. 3f). Targeting efficacy of rapamycin on these mice was confirmed based on IHC staining of p-Rps6 in these mice (Supplementary Fig. S4E). We also performed a second trial to investigate whether rapamycin treatment could inhibit tumor growth when treatment started before tumor onset (Supplementary section and Supplementary Fig. S4A-D). Collectively, rapamycin treatment delayed the PanNET and PitNET growth but did not inhibit tumor development, and rapamycin treatment increased life span but did not prevent death in MPR mice.

\section{Another GEMM developed only WD PanNETs}

The disadvantage of the RIP-Cre construct is that the Cre expression also occurs in the pituitary due to expression of the Insulin 2 gene in hypothalamus [24]. As MEN1 patients could develop both PitNETs and PanNETs in one person in some cases, this MPR model is not necessarily a disadvantage in terms of understanding the molecular mechanism of the human disease. However, it is difficult to use this model as in vivo preclinical model for PanNETs since both PanNETs and PitNETs develop in the same MPR mouse, and PitNETs are the more lethal tumors. A Cre mouse model with Cre gene expression driven by a knockin mouse Insulin 1 promoter (MIP-Cre) was recently reported to recapitulate the expression pattern of the endogenous mouse Insulin 1 gene with highly specific targeting 
Table 1 PanNET frequency in MPR mouse model

\begin{tabular}{lllllll}
\hline $\begin{array}{l}\text { Age of } \\
\text { mice } \\
\text { (weeks) }\end{array}$ & $\begin{array}{l}\text { \# of total } \\
\text { mice } \\
\text { monitored }\end{array}$ & $\begin{array}{l}\text { Tumor } \\
\text { frequency of } \\
\text { all mice }(\%)\end{array}$ & $\begin{array}{l}\text { \# of female } \\
\text { mice } \\
\text { monitored }\end{array}$ & $\begin{array}{l}\text { Tumor } \\
\text { frequency of } \\
\text { female } \\
\text { mice }(\%)\end{array}$ & $\begin{array}{l}\text { \# of male } \\
\text { mice } \\
\text { monitored }\end{array}$ & $\begin{array}{l}\text { Tumor } \\
\text { frequency of } \\
\text { male mice }(\%)\end{array}$ \\
\hline 3 & 12 & 0 & 6 & 0 & 6 & 0 \\
5 & 18 & 0 & 10 & 0 & 8 & 0 \\
7 & 23 & 8.7 & 13 & 7.7 & 10 & 10 \\
9 & 23 & 43.5 & 14 & 50 & 9 & 33.3 \\
11 & 22 & 68.2 & 16 & 68.8 & 6 & 66.7 \\
13 & 27 & 85.2 & 15 & 80 & 12 & 91.7 \\
15 & 23 & 95.7 & 6 & 100 & 17 & 94.1 \\
17 & 17 & 100 & & & 17 & 100 \\
19 & 2 & 100 & 1 & 100 & 1 & 100 \\
23 & 2 & 100 & & & 2 & 100 \\
\hline
\end{tabular}

PanNET pancreatic neuroendocrine tumor, MPR Men ${ }^{f l o x}$ flox Pten $^{\text {floxflox }}$ RIP-Cre to the pancreatic $\beta$-cells. MIP-Cre expression does not appear in the brain and other tissues [44].

We investigated whether conditional deletion of Men 1 and Pten using this promoter would also result in PanNETs. Indeed, MPM mice were healthy with a normal pituitary and developed pancreatic tumors at 24 weeks while MP littermates showed normal pituitary and normal pancreas (Fig. 4a). The tumors from MPM mice stained exclusively positive for insulin and NET markers synaptophysin and chromogranin $\mathrm{A}$, indicating that these were PanNETs (Fig. 4b). The Ki 67 index was between $0.8 \%$ and $6.84 \%$. Thus the MPM PanNETs were WD G1/G2 PanNETs consistent with MPR PanNETs.

We then evaluated the temporal appearance and frequency of tumor formation in MPM mice with the same criteria and pancreas-related protocols as with MPR mice. Based on H \& $\mathrm{E}$ and insulin and glucagon immunoreactivities, MPM mice exhibited the same multi-step tumor progression from hyperplastic islets to one tumor to more tumors as observed in the MPR mice (Supplementary Fig. S5A). Quantitatively measuring the ratio of the islets area per pancreas area confirmed that hyperplastic islets appeared at 3 weeks with progressively increasing the ratio of islets area per pancreas area as PanNETs developed while MP mice displayed consistent ratio of islets area per pancreas area at all ages (Fig. 4c). Histological evaluation of the pancreas of the cohort MPM mice indicated that around $28.6 \%$ of MPM mice developed PanNETs at 7 weeks and $100 \%$ of mice developed PanNETs at 13 weeks and later (Fig. 4d and Table 2). MPM mice developed hypoglycemia and elevated serum insulin levels as they developed PanNETs (Fig. 4f, g), indicating that these PanNETs were insulinomas, similar to MPR PanNETs. Thus the MPM model showed similar characteristics in the pancreas to MPR mice with no effect on the pituitary.

To understand whether Menin and Pten function cooperatively to suppress PanNETs in MPM mice, pancreas sections from Men $I^{\text {floxfflox }}$ MIP-Cre (MM) mice at 18 weeks and Pten ${ }^{\text {floxfflox }}$ MIP-Cre (PM) mice at 19 weeks were evaluated histologically. At this age, 100\% MPM mice developed PanNETs while MM and PM mice displayed only islet hyperplasia (Supplementary Fig. S5B). MM mice exhibited larger islets and reduced number of $\alpha$-cells and PM mice exhibited smaller islets with relatively normal distribution of $\beta$-cells and $\alpha$-cells, indicating that MM mice developed more islet abnormalities than PM mice. Quantitative measurements of the ratio of the islets area per pancreas area in the MM and PM mice of 18-19 weeks and in the MP and MPM mice of 11 weeks clearly demonstrated that concomitant loss of Menl and Pten accelerated PanNET development in MPM mice (Fig. 5a).

To test the efficacy of this MPM model in preclinical assessment, we treated the MPM mice with rapamycin ( $n$ $=13)$ and vehicle $(n=12)$ at 4 weeks before the onset of PanNET development. Treatments were ended after 5 weeks in half of the groups of mice and after 8 weeks in the rest of the groups. Histology of the pancreas was evaluated and the ratio of the islets area per pancreas area was quantitatively measured, demonstrating that rapamycin treatments delayed the PanNET growth after 5- or 8-week treatments but did not inhibit PanNET development compared to vehicle-treated littermates (Fig. 5c), as seen in MPR mice. Since MPM mice did not die by 24 weeks, this model provides a better-targeted option for in vivo preclinical therapeutic study for human PanNET patients.

\section{Discussion}

Effective models in preclinical testing are essential in improving clinical outcomes. Motivated by the need for WD PanNET models, we sought tumor suppressors that 
a

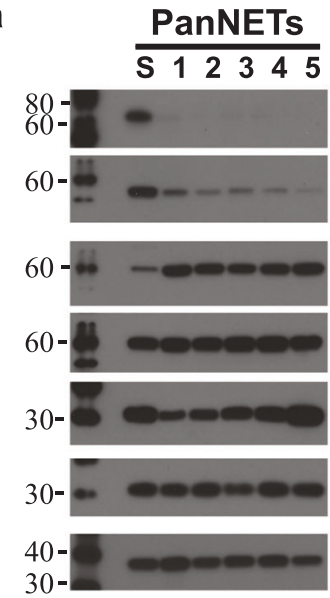

d

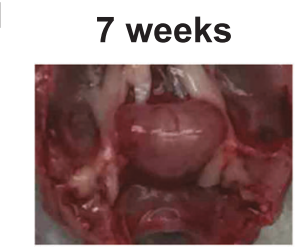

$5 \times 3.5 \times 2 \mathrm{~mm}$

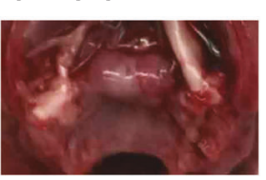

$4 \times 2 \times 2 \mathrm{~mm}$

Pretreatment

e

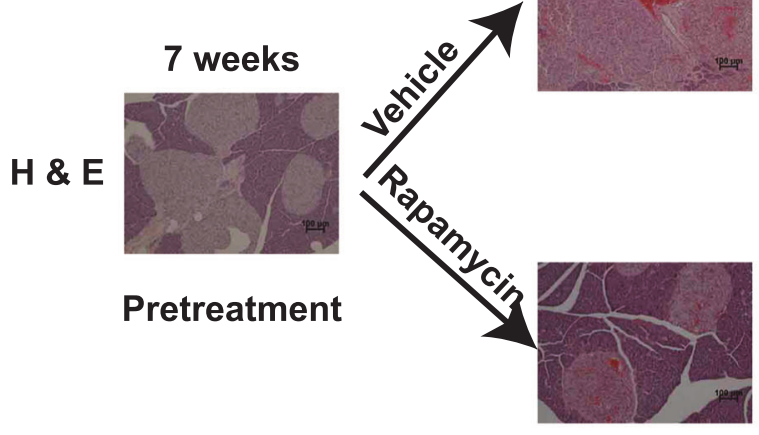

Fig. 3 Rapamycin treatments of MPR mice at the onset of tumor delayed growth of pancreatic neuroendocrine tumors (PanNETs) and pituitary neuroendocrine tumors (PitNETs). a Western blot analysis of Menin, Pten, phospho-AKT (p-Akt), total Akt, phospho-Rps6 (pRps6), total Rps6, and Gapdh proteins from 5 PanNETs and 5 PitNETs of MPR mice shown in Lanes 1-5. Lane $S$ is the spleen from one of the five MPR mice. The molecular weight markers (in $\mathrm{kD}$ ) were labeled on the left side of the blots. b-d Rapamycin treatment of MPR mice at the onset of tumor delayed growth of PitNETs and death but did not inhibit PitNET development and death in MPR mice. b Rapamycin-treated mice $(n=14)$ showed longer life span than

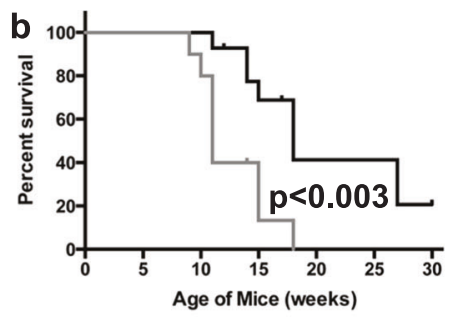

- Vehicle-Treated Mice $(n=10)$

- Rapamycin-Treated Mice $(n=14)$

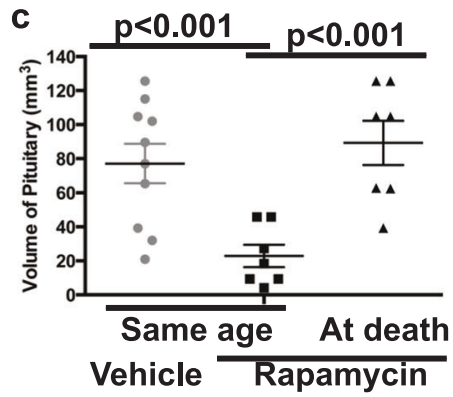

Vehicle Rapamycin
$13 \times 6 \times 2.5 \mathrm{~mm}$

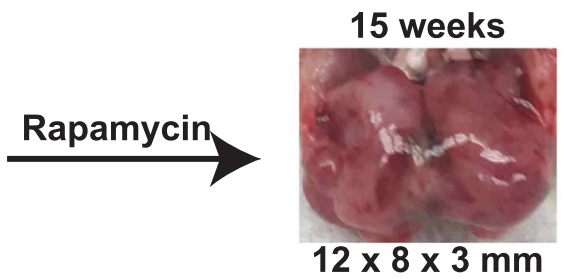

f

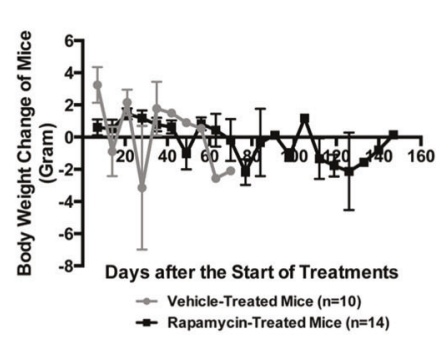

30 weeks
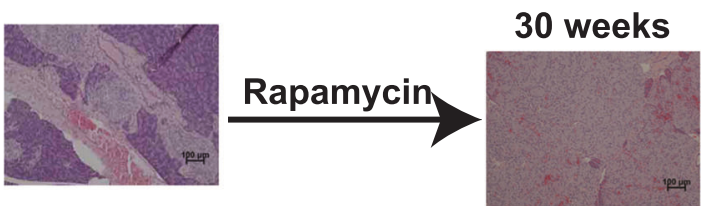

vehicle-treated MPR mice $(n=10)(p<0.003)$ in the first trial. c Size of PitNETs of vehicle-treated mice $(n=10)$ was significantly larger than rapamycin-treated mice $(n=7)$ of the same age $(p<0.001)$; size of PitNETs of rapamycin-treated mice $(n=7)$ at death/end of treatment was similar to that of vehicle-treated mice at death $(p=0.5)$. d Gross pathology of pituitary in vehicle-treated or rapamycin-treated MPR mice in the first trial. e Rapamycin treatments delayed the growth of PanNET in MPR mice- $\mathrm{H} \& \mathrm{E}$ of pancreas in vehicle-treated or rapamycin-treated MPR mice in the first trial. f Rapamycin was not toxic to mice. Weekly body weight change of rapamycin- and vehicletreated mice was shown 
a
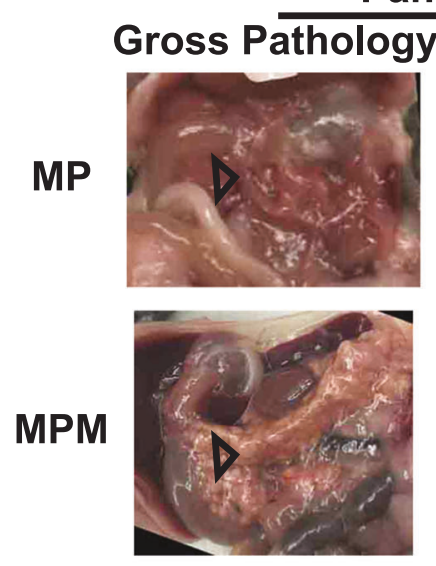

Pancreas
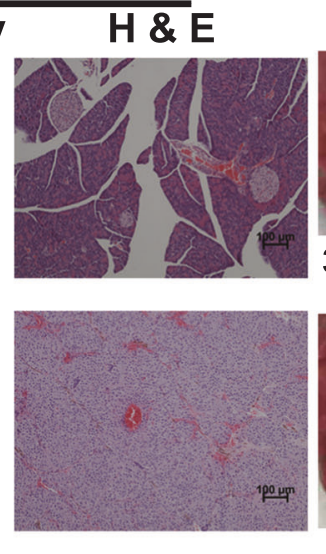

Pituitary

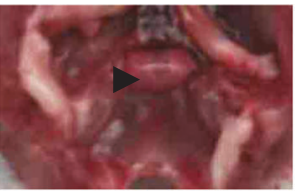

\section{4 weeks}

$3.5 \times 1.5 \times 1.5 \mathrm{~mm}$

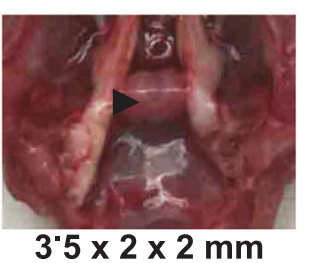

24 weeks
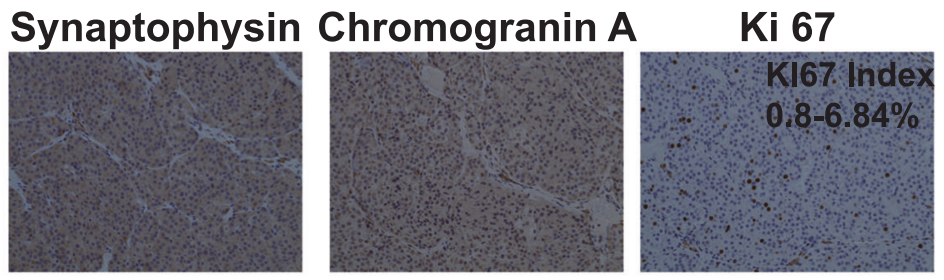

e

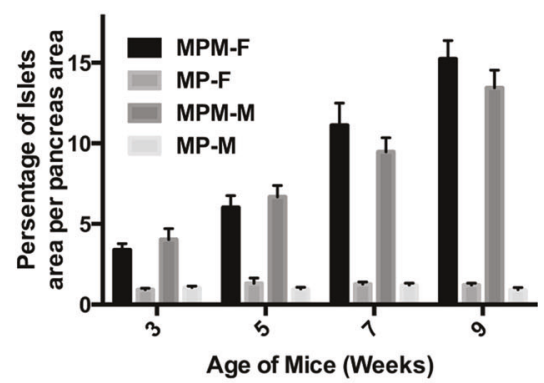

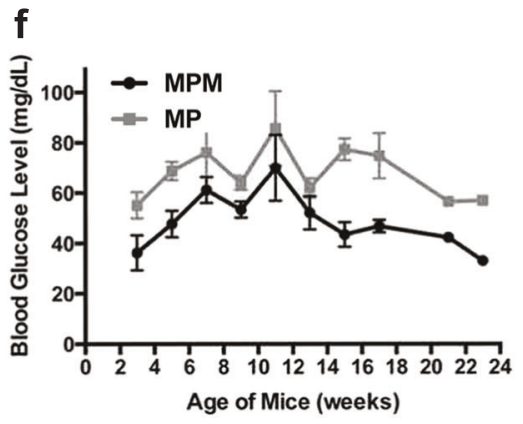

Fig. 4 Another well-differentiated pancreatic neuroendocrine tumor (PanNET) mouse model-MPM. a Gross pathology of pancreas and pituitary, and hematoxylin and eosin $(\mathrm{H} \& \mathrm{E})$ staining of pancreas at 24 weeks in MP and MPM mice. Pancreas is shown with open triangle inside the mouse abdomen and pituitary is shown with arrowhead inside the mouse brain skull. b MPM tumors were G1/G2 PanNETs$\mathrm{H} \& \mathrm{E}$ and immunohistochemical staining of insulin, synaptophysin, chromogranin A, and Ki 67 in MPM mice. Ki 67 index $(n=16)$ is shown. c Quantitative measurements of the ratio of the islet area per pancreas area in MP and MPM mice as mice aged ( $n \geq 6$ of each time point and each genotype). d Tumor frequency in MPM mice $(n=72$; examined mice at weeks of $3(n=7), 5(n=7), 7(n=7), 9(n=8), 11$ $(n=6), 13(n=10), 15(n=4), 17(n=12), 19(n=3), 21(n=5)$, and $23(n=3)$. e Quantitative measurements of the ratio of the islet area per pancreas area in female and male MP and MPM mice as mice aged ( $n \geq 3$ of each time point, each genotype, and sex). f Blood glucose levels in MP and MPM mice as mice aged ( $n=65$ for MPM $(n=7,7$, $7,8,4,10,4,12,0,5,1$ at $3,5,7,9,11,13,15,17,19,21$ and 23 weeks, respectively) and $n=64$ for MP $(n=8,8,7,7,4,12,7,7,0$, 3,1 at 3, 5, 7, 9, 11, 13, 15, 17, 19, 21 and 23 weeks, respectively)) and g serum insulin levels in MP and MPM mice as mice aged $(n=68$ for MPM $(n=6,7,7,8,5,9,4,12,3,5,2$ at 3, 5, 7, 9, 11, 13, 15, 17, 19, 21 and 23 weeks, respectively) and $n=65$ for MP $(n=8,9,8,6,5,12$, 7, 7, 1, 2, 0 at 3, 5, 7, 9, 11, 13, 15, 17, 19, 21 and 23 weeks, respectively)) MPM Men $1^{\text {flox fflox }}$ Pten floxfflox MIP-Cre, MP Men $1^{\text {floxfflox }}$ Pten $^{\text {floxfllox}}$, MM Men $1^{\text {floxfflox }}$ MIP-Cre, PM Pten ${ }^{\text {floxflox }}$ MIP-Cre 
Table 2 PanNET frequency in MPM mouse model

\begin{tabular}{lllllll}
\hline $\begin{array}{l}\text { Age of } \\
\text { mice } \\
\text { (weeks) }\end{array}$ & $\begin{array}{l}\text { \# of } \\
\text { total mice }\end{array}$ & $\begin{array}{l}\text { Tumor } \\
\text { frequency in } \\
\text { all mice }(\%)\end{array}$ & $\begin{array}{l}\text { \# of } \\
\text { female mice }\end{array}$ & $\begin{array}{l}\text { Tumor } \\
\text { frequency in } \\
\text { female } \\
\text { mice }(\%)\end{array}$ & $\begin{array}{l}\text { \# of } \\
\text { male mice }\end{array}$ & $\begin{array}{l}\text { Tumor } \\
\text { frequency in } \\
\text { male mice }(\%)\end{array}$ \\
\hline 3 & 7 & 0 & 3 & 0 & 4 & 0 \\
5 & 7 & 0 & 3 & 0 & 4 & 0 \\
7 & 7 & 28.6 & 3 & 33.3 & 4 & 25 \\
9 & 8 & 63 & 5 & 66.7 & 3 & 66.7 \\
11 & 6 & 83 & 3 & 100 & 3 & 66.7 \\
13 & 10 & 100 & 5 & 100 & 5 & 100 \\
15 & 4 & 100 & 3 & 100 & 1 & 100 \\
17 & 12 & 100 & 5 & 100 & 7 & 100 \\
19 & 3 & 100 & 3 & 100 & & 100 \\
21 & 5 & 100 & 3 & 100 & 2 & 100 \\
24 & 3 & 100 & 2 & 100 & 1 & \\
\hline
\end{tabular}

PanNET pancreatic neuroendocrine tumor, MPM Men $1^{\text {flox } f \text { flox }}$ Pten ${ }^{\text {flox } x \text { flox }}$ MIP-Cre
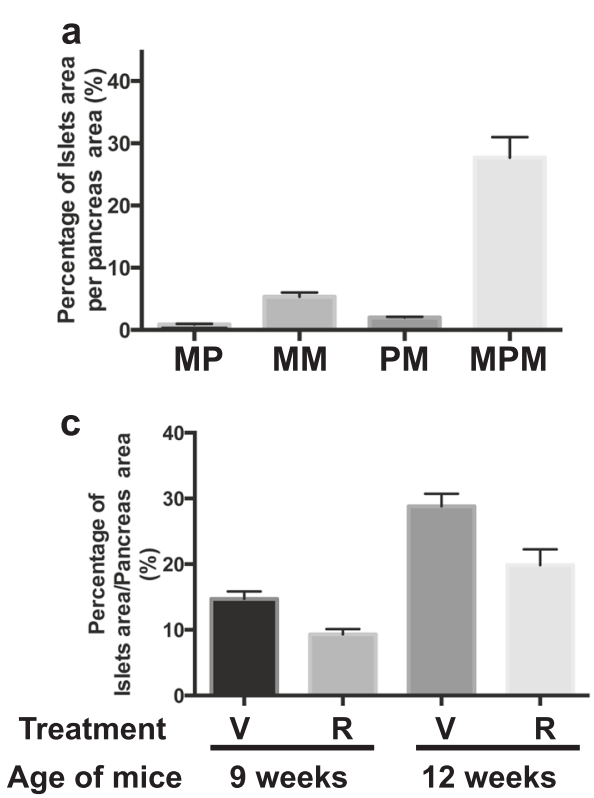

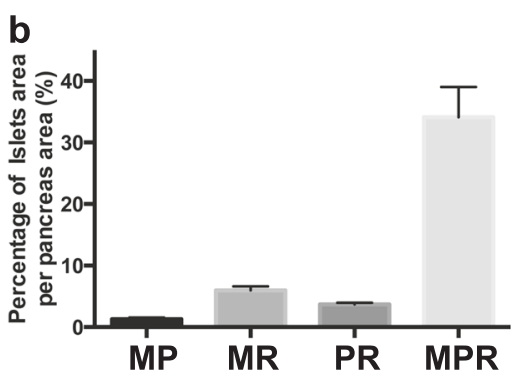

mice in preclinical rapamycin assessment. Vehicle-treated mice (V) at 9 weeks $(n=6)$, Rapamycin-treated mice $(\mathrm{R})$ at 9 weeks $(n=5)$, Vehicle-treated mice $(\mathrm{V})$ at 12 weeks $(n=6)$, Rapamycin-treated mice (R) at 12 weeks $(n=8)$. MPM Men $1^{\text {floxfllox }}$ Pten $^{\text {floxflox }}$ MIP-Cre, MP Men $1^{\text {flox } f \text { flox }}$ Pten ${ }^{\text {floxfflox }}$, MM Men $1^{\text {floxfflox }}$ MIP-Cre, PM Pten ${ }^{\text {flox fllox }}$ MIPCre, MPR Men $1^{\text {floxfflox }}$ Pten ${ }^{\text {floxfflox }}$ RIP-Cre, MR Men $1^{\text {flox } f \text { flox }}$ RIP-Cre, PR Pten ${ }^{\text {floxfflox }}$ RIP-Cre

WD G1/G2 PanNETs, which are in keeping with the human counterpart PanNETs. The PitNETs developed in MPR mice are prolactinomas, which may be the reason that female mice developed PitNETs faster and larger than male mice. The PanNETs developed in MPR and MPM mice are insulinomas and gender bias was not observed in PanNET development based on the ratio of $\beta$-cell mass and tumor 
development frequency as mice aged (Fig. $2 \mathrm{f}$ and Table 1 , Fig. 4e and Table 2).

The rapid development of NETs in MPR and MPM mice suggests that Pten and Menin function cooperatively to suppress NE tumorigenesis. The cooperative function of Menin and Pten has not been previously reported in any cancer. Our data are also the first to directly support the importance of the $\mathrm{PI} 3 \mathrm{~K} / \mathrm{AKT} / \mathrm{mTOR}$ pathway in NE tumorigenesis in mice. It has been reported that Pten deletion does not lead to tumorigenesis in $\beta$-cells in mice $[42,45,46]$, even with the co-activation of c-Myc. However, our MPR and MPM models demonstrate that Pten deletion plays a role in tumorigenesis in $\beta$-cells. This suggests that Pten function cooperatively with Menin but not with c-Myc. Our analysis of the ratio of the islets area per pancreas area between MR and PR and between MM and PM (Fig. 5a, b) suggests that Pten plays a less dominant role than Menin in tumorigenesis of $\beta$-cells. In addition, our MPR model suggests that Pten deletion plays a role in tumorigenesis of pituitary, which has not been reported before. PR mice showed faster growth of pituitary than MR (Fig. 1e) and displayed PitNETs eventually (Data not shown), suggesting that Pten may play a more dominant role than Menin in tumorigenesis of pituitary. The functional consequence of Menin inactivation is the loss of H3K4me3 on the promoters of Menin-regulated genes, which leads to downregulation of these genes [47]. In endocrine pancreas, Menin-regulated genes are cyclindependent kinase inhibitors $p 18$ and $p 27$ [48]. Our evaluation on the expression of p27 and p18 in the MPR and MR tumors suggested low or undetected protein expression in MR and MPR tumors (data not shown). Since it has been reported that Pten controls cell cycle by decreasing cyclin D and increasing p27 expression [49], cooperativity of Menin and Pten in NE tumorigenesis may be through regulation of p27. Further investigation of how Menin-mediated and $\mathrm{PI} 3 \mathrm{~K} / \mathrm{AKT} / \mathrm{mTOR}$ signaling pathways function cooperatively is worth pursuing.

The Men1 mouse models closely resemble human MEN1 disease but develop PanNETs at a delayed latency, which is not an ideal preclinical model. The RIP-Tag2 mouse model is well characterized with tumor onset at 10 weeks and has proven effective in drug testing for the treatment of advanced PanNETs [12, 50, 51]. However, RIP-Tag2 mice develop high-grade WD G3 PanNETs and PD PanNECs, which are uncommon in human counterpart PanNETs [15]. In addition, the mouse has a T-antigen not found in human and co-mutations of tumor suppressors $\mathrm{Rb}$ and p53 have not been reported in human PanNETs. Our MPR and MPM models have the advantages of both Men1 and RIP-Tag2 mouse models. The MPR and MPM models mimic human MEN1-like disease and develop WD G1/G2 PanNETs. Also, co-mutations of PTEN and MEN1 have been found in $8.8 \%$ [32] or $13.3 \%$ [21] of human PanNET patients with somatic MENI mutations and in 50\% [32] or $80 \%$ [21] of human PanNET patients with somatic PTEN mutations. Like the RIP-Tag2 model, the MPR and MPM models have an earlier onset of PanNETs. Consistent with expectations for such models, the mice were responsive to the well-established rapamycin treatment. Specifically, MPM model develops only PanNETs, allowing preclinical study of drug candidates for WD PanNETs. Our models will complement the RIP-Tag2 mouse model in PanNET therapeutic research $[12,50]$.

In summary, we demonstrate for the first time that Menin and Pten function cooperatively in suppression of $\mathrm{NE}$ tumorigenesis in pancreas and pituitary and have developed two WD PanNET mouse models, which will permit a more detailed exploration of the pathways in NETs. With their similarity to human NETs, these models could prove valuable in preclinical investigation of much needed new therapies for these indolent but progressive and often fatal tumors.

Acknowledgements We sincerely thank Richard Clausen for breeding the mice and performing genotyping for the project. We would like to thank the Raymond and Beverly Sackler Foundation for their support of our research. We thank Histopathology Services and the Biomedical Imaging shared resources of Rutgers Cancer Institute of New Jersey (P30CA072720) for their support and help.

Financial support This work was supported by the Raymond \& Beverly Sackler Foundation.

\section{Compliance with ethical standards}

Conflict of interest The authors declare that they have no conflict of interest.

Publisher's note: Springer Nature remains neutral with regard to jurisdictional claims in published maps and institutional affiliations.

Open Access This article is licensed under a Creative Commons Attribution 4.0 International License, which permits use, sharing, adaptation, distribution and reproduction in any medium or format, as long as you give appropriate credit to the original author(s) and the source, provide a link to the Creative Commons license, and indicate if changes were made. The images or other third party material in this article are included in the article's Creative Commons license, unless indicated otherwise in a credit line to the material. If material is not included in the article's Creative Commons license and your intended use is not permitted by statutory regulation or exceeds the permitted use, you will need to obtain permission directly from the copyright holder. To view a copy of this license, visit http://creativecommons. org/licenses/by/4.0/.

\section{References}

1. Bosman FT, Carneiro F, Hruban RH, Theise ND. World Health Organization (WHO) Classification of Tumours of the Digestive System. Lyon: IARC Press; 2010. 
2. Tang LH, Untch BR, Reidy DL, O'Reilly E, Dhall D, Jih L, et al. Well-differentiated neuroendocrine tumors with a morphologically apparent high-grade component: a pathway distinct from poorly differentiated neuroendocrine carcinomas. Clin Cancer Res. 2016;22:1011-7.

3. Scoazec JY, Couvelard A, Reseau T. [Classification of pancreatic neuroendocrine tumours: Changes made in the 2017 WHO classification of tumours of endocrine organs and perspectives for the future]. Ann Pathol. 2017;37:444-56.

4. Guilmette JM, Nose V. Neoplasms of the neuroendocrine pancreas: an update in the classification, definition, and molecular genetic advances. Adv Anat Pathol. 2018;26(1):13-30.

5. Yao JC, Shah MH, Ito T, Bohas CL, Wolin EM, Van Cutsem E, et al. Everolimus for advanced pancreatic neuroendocrine tumors. N Engl J Med. 2011;364:514-23.

6. Yao JC, Pavel M, Phan AT, Kulke MH, Hoosen S, St Peter J, et al. Chromogranin A and neuron-specific enolase as prognostic markers in patients with advanced pNET treated with everolimus. J Clin Endocrinol Metab. 2011;96:3741-9.

7. Raymond E, Dahan L, Raoul JL, Bang YJ, Borbath I, LombardBohas C, et al. Sunitinib malate for the treatment of pancreatic neuroendocrine tumors. N Engl J Med. 2011;364:501-13.

8. Strosberg J, Wolin E, Chasen B, Kulke M, Bushnell D, Caplin M, et al. Health-related quality of life in patients with progressive midgut neuroendocrine tumors treated with (177)Lu-dotatate in the phase III NETTER-1 trial. J Clin Oncol. 2018;36:2578-84.

9. Moreno A, Akcakanat A, Munsell MF, Soni A, Yao JC, MericBernstam F. Antitumor activity of rapamycin and octreotide as single agents or in combination in neuroendocrine tumors. Endocr Relat Cancer. 2008;15:257-66.

10. Chiu CW, Nozawa H, Hanahan D. Survival benefit with proapoptotic molecular and pathologic responses from dual targeting of mammalian target of rapamycin and epidermal growth factor receptor in a preclinical model of pancreatic neuroendocrine carcinogenesis. J Clin Oncol. 2010;28:4425-33.

11. Olson P, Chu GC, Perry SR, Nolan-Stevaux O, Hanahan D. Imaging guided trials of the angiogenesis inhibitor sunitinib in mouse models predict efficacy in pancreatic neuroendocrine but not ductal carcinoma. Proc Natl Acad Sci USA. 2011;108: E1275-84.

12. Hanahan D. Heritable formation of pancreatic beta-cell tumours in transgenic mice expressing recombinant insulin/simian virus 40 oncogenes. Nature. 1985;315:115-22.

13. Evers BM, Townsend CM Jr., Upp JR, Allen E, Hurlbut SC, Kim $\mathrm{SW}$, et al. Establishment and characterization of a human carcinoid in nude mice and effect of various agents on tumor growth. Gastroenterology. 1991;101:303-11.

14. Wong C, Vosburgh E, Levine AJ, Cong L, Xu EY. Human neuroendocrine tumor cell lines as a three-dimensional model for the study of human neuroendocrine tumor therapy. J Vis Exp. 2012;66:e4218

15. Hunter KE, Quick ML, Sadanandam A, Hanahan D, Joyce JA. Identification and characterization of poorly differentiated invasive carcinomas in a mouse model of pancreatic neuroendocrine tumorigenesis. PLoS ONE. 2013;8:e64472.

16. Thakker RV. Multiple endocrine neoplasia type 1 (MEN1). Best Pract Res Clin Endocrinol Metab. 2010;24:355-70.

17. Thakker RV. Multiple endocrine neoplasia type 1 (MEN1) and type 4 (MEN4). Mol Cell Endocrinol. 2014;386:2-15.

18. Thakker RV, Newey PJ, Walls GV, Bilezikian J, Dralle H, Ebeling PR, et al. Clinical practice guidelines for multiple endocrine neoplasia type 1 (MEN1). J Clin Endocrinol Metab. 2012;97:2990-3011.

19. Marini F, Giusti F, Tonelli F, Brandi ML. Management impact: effects on quality of life and prognosis in MEN1. Endocr Relat Cancer. 2017;24:T227-T42.
20. Guru SC, Goldsmith PK, Burns AL, Marx SJ, Spiegel AM, Collins FS, et al. Menin, the product of the MEN1 gene, is a nuclear protein. Proc Natl Acad Sci USA. 1998;95:1630-4.

21. Jiao Y, Shi C, Edil BH, de Wilde RF, Klimstra DS, Maitra A, et al. DAXX/ATRX, MEN1, and mTOR pathway genes are frequently altered in pancreatic neuroendocrine tumors. Science. 2011;331:1199-203.

22. Mohr H, Pellegata NS. Animal models of MEN1. Endocr Relat Cancer. 2017;24:T161-T77.

23. Bertolino P, Tong WM, Herrera PL, Casse H, Zhang CX, Wang ZQ. Pancreatic beta-cell-specific ablation of the multiple endocrine neoplasia type 1 (MEN1) gene causes full penetrance of insulinoma development in mice. Cancer Res. 2003;63:4836-41.

24. Biondi CA, Gartside MG, Waring P, Loffler KA, Stark MS, Magnuson MA, et al. Conditional inactivation of the MEN1 gene leads to pancreatic and pituitary tumorigenesis but does not affect normal development of these tissues. Mol Cell Biol. 2004;24:3125-31.

25. Crabtree JS, Scacheri PC, Ward JM, McNally SR, Swain GP, Montagna $\mathrm{C}$, et al. Of mice and MEN1: insulinomas in a conditional mouse knockout. Mol Cell Biol. 2003;23:6075-85.

26. Zhuang Z, Ezzat SZ, Vortmeyer AO, Weil R, Oldfield EH, Park WS, et al. Mutations of the MEN1 tumor suppressor gene in pituitary tumors. Cancer Res. 1997;57:5446-51.

27. Zhuang Z, Vortmeyer AO, Pack S, Huang S, Pham TA, Wang C, et al. Somatic mutations of the MEN1 tumor suppressor gene in sporadic gastrinomas and insulinomas. Cancer Res. 1997;57:4682-6.

28. Shen HC, He M, Powell A, Adem A, Lorang D, Heller C, et al. Recapitulation of pancreatic neuroendocrine tumors in human multiple endocrine neoplasia type I syndrome via Pdx1-directed inactivation of Men1. Cancer Res. 2009;69:1858-66.

29. Tamborero D, Gonzalez-Perez A, Perez-Llamas C, Deu-Pons J, Kandoth C, Reimand J, et al. Comprehensive identification of mutational cancer driver genes across 12 tumor types. Sci Rep. 2013;3:2650.

30. Missiaglia E, Dalai I, Barbi S, Beghelli S, Falconi M, della Peruta $\mathrm{M}$, et al. Pancreatic endocrine tumors: expression profiling evidences a role for AKT-mTOR pathway. J Clin Oncol. 2010;28: 245-55.

31. Kasajima A, Pavel M, Darb-Esfahani S, Noske A, Stenzinger A, Sasano H, et al. mTOR expression and activity patterns in gastroenteropancreatic neuroendocrine tumours. Endocr Relat Cancer. 2011;18:181-92.

32. Scarpa A, Chang DK, Nones K, Corbo V, Patch AM, Bailey P, et al. Whole-genome landscape of pancreatic neuroendocrine tumours. Nature. 2017;543:65-71.

33. Chou WC, Lin PH, Yeh YC, Shyr YM, Fang WL, Wang SE, et al. Genes involved in angiogenesis and mTOR pathways are frequently mutated in Asian patients with pancreatic neuroendocrine tumors. Int J Biol Sci. 2016;12:1523-32.

34. Perren A, Komminoth P, Saremaslani P, Matter C, Feurer S, Lees $\mathrm{JA}$, et al. Mutation and expression analyses reveal differential subcellular compartmentalization of PTEN in endocrine pancreatic tumors compared to normal islet cells. Am J Pathol. 2000;157:1097-103.

35. Chung DC, Brown SB, Graeme-Cook F, Tillotson LG, Warshaw $\mathrm{AL}$, Jensen RT, et al. Localization of putative tumor suppressor loci by genome-wide allelotyping in human pancreatic endocrine tumors. Cancer Res. 1998;58:3706-11.

36. Rigaud G, Missiaglia E, Moore PS, Zamboni G, Falconi M, Talamini G, et al. High resolution allelotype of nonfunctional pancreatic endocrine tumors: identification of two molecular subgroups with clinical implications. Cancer Res. 2001;61:285-92.

37. Lamberti G, Brighi N, Maggio I, Manuzzi L, Peterle C, Ambrosini $\mathrm{V}$, et al. The role of mTOR in neuroendocrine tumors: future cornerstone of a winning strategy? Int J Mol Sci. 2018;19:E747. 
38. Liu IH, Ford JM, Kunz PL. DNA-repair defects in pancreatic neuroendocrine tumors and potential clinical applications. Cancer Treat Rev. 2016;44:1-9.

39. Gannon M, Shiota C, Postic C, Wright CV, Magnuson M. Analysis of the Cre-mediated recombination driven by rat insulin promoter in embryonic and adult mouse pancreas. Genesis. 2000;26:139-42.

40. Lesche R, Groszer M, Gao J, Wang Y, Messing A, Sun H, et al. Cre/loxP-mediated inactivation of the murine Pten tumor suppressor gene. Genesis. 2002;32:148-9.

41. Wong C, Laddha SV, Tang L, Vosburgh E, Levine AJ, Normant E, et al. The bromodomain and extra-terminal inhibitor CPI203 enhances the antiproliferative effects of rapamycin on human neuroendocrine tumors. Cell Death Dis. 2014;5:e1450.

42. Nguyen KT, Tajmir P, Lin CH, Liadis N, Zhu XD, Eweida M, et al. Essential role of Pten in body size determination and pancreatic beta-cell homeostasis in vivo. Mol Cell Biol. 2006;26:4511-8.

43. Verges B, Boureille F, Goudet P, Murat A, Beckers A, Sassolas G, et al. Pituitary disease in MEN type 1 (MEN1): data from the France-Belgium MEN1 multicenter study. J Clin Endocrinol Metab. 2002;87:457-65.

44. Thorens B, Tarussio D, Maestro MA, Rovira M, Heikkila E, Ferrer J. Ins1(Cre) knock-in mice for beta cell-specific gene recombination. Diabetologia. 2015;58:558-65.
45. Radziszewska A, Choi D, Nguyen KT, Schroer SA, Tajmir P, Wang L, et al. PTEN deletion and concomitant c-Myc activation do not lead to tumor formation in pancreatic beta cells. J Biol Chem. 2009;284:2917-22.

46. Stiles BL, Kuralwalla-Martinez C, Guo W, Gregorian C, Wang Y, Tian J, et al. Selective deletion of Pten in pancreatic beta cells leads to increased islet mass and resistance to STZ-induced diabetes. Mol Cell Biol. 2006;26:2772-81.

47. Dreijerink KMA, Timmers HTM, Brown M. Twenty years of menin: emerging opportunities for restoration of transcriptional regulation in MEN1. Endocr Relat Cancer. 2017;24: T135-45.

48. Matkar S, Thiel A, Hua X. Menin: a scaffold protein that controls gene expression and cell signaling. Trends Biochem Sci. 2013;38:394-402.

49. Chu IM, Hengst L, Slingerland JM. The Cdk inhibitor p27 in human cancer: prognostic potential and relevance to anticancer therapy. Nat Rev Cancer. 2008;8:253-67.

50. Tuveson D, Hanahan D. Translational medicine: cancer lessons from mice to humans. Nature. 2011;471:316-7.

51. Pietras K, Hanahan D. A multitargeted, metronomic, and maximum-tolerated dose "chemo-switch" regimen is antiangiogenic, producing objective responses and survival benefit in a mouse model of cancer. J Clin Oncol. 2005;23:939-52. 